Abstract AB0164 Table 1

\begin{tabular}{|c|c|c|c|c|c|c|c|c|c|}
\hline & Low back pain & Dorsal pain & Cervical pain & Headaches & Dizziness & Astenopia & Unbalance & Vertigo & Migraine \\
\hline Frequency $n=100$ & $60 \%$ & $41 \%$ & $55 \%$ & $47 \%$ & $45 \%$ & $44 \%$ & $37 \%$ & $30 \%$ & $23 \%$ \\
\hline Improv. aft treatm & $37 \%$ & $28 \%$ & $32 \%$ & $33 \%$ & $28 \%$ & $28 \%$ & $30 \%$ & $15 \%$ & $18 \%$ \\
\hline Wilcoxon test & $p=0.001$ & $p=0.02$ & $P=0.001$ & $p=0.000$ & $p=0.000$ & $p=0.005$ & $p=0.002$ & $p=0.02$ & $p=0.05$ \\
\hline
\end{tabular}

treatment with plantars and/or prismatic lenses correction (legs length dismetry, functional and structural scoliosis).

Methods A group of 100 patients with postural symptoms were evaluated and treated in our institution for more than 36 months. Their symptoms were graduated from 0 to 4 and compared before and after a year of treatment. An x-ray film of the rachis from anteroposterior view was obtained. The aim of the corrections was to obtain the nearest horizontal equilibrium for the different plans of the body and equal distribution of weight. Leg length dismetry was corrected according to the position of the femoral heads and searching for the relative inclination degree of both femoral heads and sacred with the horizontal plan. Correction with prismatic lenses was performed in the cases without leg length dismetry, horizontal sacral base, inclination of the head or shoulder plans.

Results Of the 100 patients, 71 were female and reported mean age $33.7 \pm 20.2$ SD years. The symptoms more commonly found are shown in table below by frequency sequence at first observation. Improvement after completed treatment was obtained for all analysis symptoms with statistical significance except for temporomandibular joint, hip, knee and foot pain.

Conclusion The treatment of different postural symptoms with plantars, prismatic lenses or both together revealed a global improvement in low back and cervical pain, dizziness, astenopia, headache, dorsal pain, unbalance, migraine, vertigo. The different treatments analysed revealed a clinically significant improvement in low back pain $(p=0,001)$, cervical pain $(p=0,001)$, headache $(\mathrm{p}=0,000)$, dizziness $(\mathrm{p}=0,000)$, astenopia $(\mathrm{p}=$ $0,005)$, dorsal pain $(\mathrm{p}=0,022)$, unbalance $(\mathrm{p}=0,002)$, vertigo $(\mathrm{p}=0,027)$, migraine $(\mathrm{p}=0,05)$. This statistical significance improvement difference is higher with the follow-up.

\section{FRI0232 IMPORTANCE OF THE RADIOLOGICAL STUDIES IN THE DIAGNOSIS OF THE CHRONIC LOW BACK PAIN}

FP Pérez-Torres, D Ybañez-García, P Pérez-Caballero, M Morales, A Llópis. Reumathology, Hospital General Requena, Requena, España

\subsection{6/annrheumdis-2001.536}

\section{Background}

Objectives Classify the radiological alterations in patients with chronic low back pain (LBP) and to determine their relationship with symptomatology, and value the contribution carried out in the classification by diagnostic groups.

Methods A longitudinal study of patients that required specialised attendance in the period of time January $95-96$ by LBP. All patients were carried a standard radiological study out and the found alterations were classified as alterations of the development and the statics, of the articulate space and of the bony density. Classified the patients in a retrospective way it was determined the contribution of the radiology like confirmed case, probable case, possible case and no case. A statistical study was realised determining absolute and relative frequencies, and $\chi^{2}$ test with a level of trust of $95 \%$.

Results Of a total of 472 selected patients, 334 presented alterations of the static $(70,8 \%)$ and it was a significant relationship between these alterations and all the diagnostic groups for a value of $\mathrm{p}<0.0001$, except for the groups inflammatory illnesses and alterations for physical agents. Alterations of the articulate space in 362 cases $(76,7 \%)$, with a significant relationship between these alterations and the spondyloarthropaty $(\mathrm{p}<$ 0.001), degenerative modifications and bony illnesses $(\mathrm{p}<$ $0.0001)$. Alterations of the bony density in 361 cases $(76,4 \%)$, with a significant relationship for all the groups $(p<0.001)$ except functional dysfunctions and physical agents.

The value of the radiology in the classification of patients was useful $(\mathrm{p}<0.0001)$ in the spondyloarthropaty groups and anomalies of the development, it didn't have value $(\mathrm{p}<0.0001)$ in functional dysfunctions and physical agents. Orientation value as possible-probable case $(\mathrm{p}<0.0001)$ in the degenerative modifications groups and bony metabolic illnesses.

Conclusion 1. Radiological signs predictor of classification are the sclerosis and the ankylosis of sacroiliac joint for the inflammatory illnesses, spondylolysis/spondylolisthesis for anomalies of the development and increase of the discal space for metabolic bony illnesses. 2. The radiology is useful to classify in the inflammatory illnesses and anomalies of the development, it hasn't value in the functional dysfunctions groups and alterations for physical agents, it has an orientation value in degenerative modifications groups and bony illnesses. 3. A 15\% of the cases have bony alterations that aren't related with the simptomatology and the diagnosis.

\section{REFERENCES}

1 Gehweiler JA, Daffner RH. Low back pain: the controversia of radiologic evaluation. AJR 1983;140:109-12

2 Suarez-Almazor ME, Belseck E, Russell AS, Mackel JV. Use of lumbar radiographs for the early diagnosis of low back pain. J Am Med Assoc. 1997;277:1782-6

\section{FRI0233 LOW BACK PAIN FROM “THE JOINT AND BONE DECADE PERSPECTIVE"}

RM Baddoura. Epidemiology Unit, Medical Faculty Saint Joseph University, Beirut, Lebanon

\subsection{6/annrheumdis-2001.537}

Background Low back pain (LBP) is a common health problem yet it still raises controversies about rationales for appropriate and cost effective management. LBP burden is reported to be higher in developing compared to developed countries in the absence of an adequate work leave compensation system.

Objectives Estimate LBP prevalence, assess risk factors and evaluate the impact in term of work leave.

Methods Three observational studies were conducted between 1997 and 1999. The first was population based on a random sample of 1035 adults asked to report on LBP over the past week. The second was conducted among nursing profession 
looking at LBP occurrence fever the past month in a sample of 633 subjects. The third was in an occupational setting addressing past history of LBP and included 201 individuals.

Results Among adults, prevalence of LBP at any given day was 13.1 (CI:11.0-14.2). Mean age is $41.8(\mathrm{SD}: 16.3)$ and $\mathrm{M} / \mathrm{F}$ ratio is 0.7 . A history of trauma was recorded by $13.2 \%(7.5-18.9)$ of LBP cases.

Among nurses, 54\% had experienced LBP over the past month. Handling patients was related to LBP by $60 \%$ (CI:5565 ) of nurses.

In an occupational setting, heavy workload is associated with higher frequency of LBP. $30.7 \%$ of those seeking medical care were offered a sick leave.

Conclusion At any given day,13.1\% (CI: 11.0-14.2) of adult population would report acute LBP. Workload is related to LBP occurrence. Sick leave is commonly prescribed for LBP.

\section{FRI0234 THE CORRELATION OF SPINAL CANAL DIMENSIONS AND CLINICAL FINDINGS IN LUMBAR SPINAL STENOSIS}

N Keser, OF Sendur, G Gurer, A Aydeniz. ADU Physical Medicine and Rehabilitation, ADU Medical School Hospital, Aydýn, Turkey

\subsection{6/annrheumdis-2001.538}

Background Spinal stenosis is narrowing of spinal canal, nerve root canal and intervertebral foramen under a critical value. Spinal degeneration is the most important reason for spinal stenosis. In most of the patient locomotor system examination is non-specific. Therefore detailed radiological examination should be done in order to make a definite diagnosis of spinal stenosis.

Objectives This study was carried out to investigate the correlation between lumbar spinal canal dimensions and clinical findings of patients who have suspected to have spinal stenosis.

Methods Forty patients ( 29 female, 11 male) were taken into this study. Detailed physical examination of locomotor system was done for each patient (lumbar range of motion, pain in lumbar extension, milligram test, muscle strength, deep tendon reflexes and sensory deficit).

CT scan of L3-L5 vertebrae level were done in order to measure A-P diameter of spinal canal, interpedicular distance, pedicular height.

Mann-Whitney U test was used for statistical analysis of data. Results We observed significant correlation between clinical findings of milligram test, pain in lumbar extansion, sensory deficit in lower extremities, deep tendon reflexes deficiency and some of CT scan results (A-P diameter and interpedicular distance of L4-L5) of patients who have spinal stenosis. There was no significant correlation between spinal stenosis and clinical findings of muscle strength deficit and lumbar ROM limitation

Conclusion We concluded that CT scan measurement and clinical findings of spinal stenosis correlate well. However soft tissues couldn't be evaluated properly and it is well known that these tissues may lead to spinal stenosis too. MRI is expensive and CT-myelography is not so easy to apply. Because of that CT is a useful technique when compared to others.

\section{REFERENCES}

1 Verbiest H. Lumbar spinal stenosis. In: Youmans JR, ed. Neurological surgery. Philadelphia: WB Saunders, 1990: 2805-55

2 Hall S, Lowthian PJ. Lumbar spinal stenosis. In: Klippel JH, Dieppe PA, eds. Rheumatology. St Louis: Mosby, 1998, 4.5.1-6

\section{FRI0235 ANALGESIC EFFICACY OF TRAMADOL/PIROXICAM COMBINATION: CLINICAL ASPECTS}

K Sekelj-Kauzlaric, B Matanovic, N Kauzlaric, R Cop, S Potrebica. Special Hospital for Medicine Rehabilitation, Hospital of Toplice, Toplice, Croatia, Outpatient Clinic for Rheumatology, FM\&R, Zagreb, Croatia

\subsection{6/annrheumdis-2001.539}

\section{Background}

Objectives To evaluate the efficacy and safety of combination analgesic tramadol/piroxicam for the treatment of low back pain. Methods This 2- week study took place in two REHA-Centres in Croatia. Patients took medication as needed for the treatment of acute low back pain and/or osteoarthritis pain. They were given $20 \mathrm{mg}$ of piroxicam in the morning and $50 \mathrm{mg}$ of tramadol every $12 \mathrm{~h}$ for 15 days. Patients reported maximum pain relief (VAS scale 0 to 10) and rated overall efficacy (scale $1=$ poor to $5=$ excellent) at the final visit. Adverse events (AEs) were monitored throughout the study.

Results A total of 70 patients from two REHA-Centres provided data. We present the analysis of age, sex and profession. Most of our patients $(61 \%)$ were employed. Our patients needed therapy for osteoarthritis pain (52\%), low back pain (40\%) and other (osteoporosis, RA, SA) 8\%. After 15 days combination tramadol/ piroxicam provided pain relief (range 2,5 ? 3,5). Overall efficacy of combination was rated $35 \%$ ?very good? or ?excellent? by $20 \%$, ?good? by $35 \%$ and ?poor? by $10 \%$ only. There were no serious or unexpected AEs. The most common AEs were: nausea $20 \%$, constipation $18 \%$, headache $16 \%$, dizziness $12 \%$ and somnolence $8 \%$.

Conclusion This study demonstrated that the combination analgesic tramadol/piroxicam is effective and well tolerated in patients with low back pain and/or ostheoarthritis.

\section{FRI0236 THE EFFECTS OF LOW-ENERGY LASER AND EXERCISE THERAPY IN PATIENTS WITH CHRONIC LOW BACK PAIN: A DOUBLE-BLIND CONTROLLED TRIAL}

M Karakoç, A Gür, K Nas, R Çevik, AJ Saraç, F Erdoðan, M Karakoç (Çelik). Physical Medicine and Rehabilitation, Dicle University, Diyarbakyr, Turkey

10.1136/annrheumdis-2001.540

Background Low back pain is a ubiquitous health, problem and leads to majör problems. Low-energy laser biostimulation can be used to treat low back pain in last years.

Objectives The aim of this double-blind controlled clinical study is to evaluate the effectiveness laser and combined exercise + laser in patients with chronic low back pain.

Methods Forty patients with chronic low back pain randomly divided into two groups of 20 patients. 20 patients in the first group received low-energy laser + exercise treatment, other group received low-energy laser treatment alone. The parameters such as pain and muscle strength were assessed in all patients pretreatment and posttreatment. Pain measurement was done using the visual anologue scale. Muscle strength measurement (m. rectus abdominus, oblicus, hip abductors, hip adductors, extensors and internal rotators, knee flexors and extansors, foot flexors and extansors, and dorsal extansors) was done using the manual muscle strength testing.

Results Both groups demonstrated significant improvements visual analogue scale and rectus abdominus, hip adductors and abductors in posttreatment $(\mathrm{p}<0.05)$, but no relative advantage was found for either group ( $p>0.05)$. 